\title{
NEOSPOROSIS EN BOVINOS LECHEROS EN DOS DISTRITOS DE LA PROVINCIA DE CHACHAPOYAS
}

\author{
Janios Quevedo V. ${ }^{1}$, Amanda Chávez V., ${ }^{2,3}$, Hermelinda Rivera G. ${ }^{2}$, Eva Casas A. ${ }^{2}$ y \\ Enrique Serrano M. ${ }^{2}$
}

\section{AbStract}

Neosporosis is a parasitic disease caused by the protozoan Neospora caninum, and is associated with high rates of abortion in cattle throughout the world. The aim of the study was to determinate the seroprevalence of $N$. caninum in dairy cattle reared in the districts of Molinopampa and Leymebamba, Chachapoyas province, Amazonas. The study was carried out in 2002 using 265 serum samples from cows older than 2 years old that belonged to 24 dairy herds. Samples were tested to detect antibodies against $N$. caninum using the IFAT test. The $40.4 \pm 5.0 \%$ (107/265) of the samples had antibodies in 1:200 dilution. All sampled herds had at least one seropositive animal. The prevalence of the parasite was similar in both districts and similar to described in herds from other dairy areas in the country.

Key words: bovine, Neospora caninum, IFAT, seroprevalence, antibodies, herd

\section{Resumin}

Neosporosis es una enfermedad parasitaria causada por el protozoo Neospora caninum, y que está asociada con altas tasas de aborto en el ganado bovino a nivel mundial. El objetivo del presente estudio fue conocer la seroprevalencia de N. caninum en bovinos lecheros de crianza extensiva de los distritos de Molinopampa y Leymebamba, provincia de Chachapoyas, Amazonas. Con esta finalidad, en el año 2002 se analizó 265 muestras de sueros de vacas mayores de 2 años, que estaban distribuidas en 24 ganaderías, para la detección de anticuerpos contra $N$. caninum mediante la prueba de Inmunofluorescencia Indirecta (IFI). El 40.4 $\pm 5.0 \%$ (107/265) de las muestras presentaron anticuerpos en una dilución de 1:200 sin diferencias estadísticas entre los distritos evaluados. Todos los hatos muestreados tuvieron animales seroreactores. La prevalencia encontrada fue similar a lo descrito en las principales cuencas lecheras del país.

Palabras clave: bovinos, Neospora caninum, IFI, seroprevalencia, anticuerpos, hato

${ }^{1}$ Práctica privada

${ }^{2}$ Laboratorio de Microbiología y Parasitología Veterinaria, FMV-UNMSM

${ }^{3}$ E-mail: a_chavez_g@hotmail.com 


\section{INTRODUCCIÓN}

Una de las enfermedades parasitarias que está causando gran daño a la economía del sector ganadero a nivel mundial es la neosporosis, cuyo agente causal es el Neospora caninum; un protozoario que ha adquirido gran importancia por alcanzar importantes índices de prevalencia a nivel mundial, y estar implicado como uno de los principales agentes causales de aborto (Thilsted y Dubey, 1989).

Fue reportado por primera vez en Noruega en 1984 como un protozoario no identificado muy parecido a Toxoplasma gondii (Bjerkas et al., 1984), teniendo como hospedero definitivo al perro (McAllister et al., 1988).

La neosporosis bovina está considerada como una de las causas de falla reproductiva (aborto y mortalidad neonatal) más importante en el ganado bovino. Aunque el aborto se considera el efecto más adverso de la infección, y ocurre entre el tercer y noveno mes de gestación; se tiene que tener en cuenta otras repercusiones, tales como la reducción en el número de terneros, mayor número de inseminaciones, repetición de celos, baja de la producción de leche y el costo por sacrificio prematuro o venta de los animales infectados. Las pérdidas económicas estimadas en países como Suiza, EE.UU. y Australia estarían alrededor de 5, 35 y 85 millones de dólares por año, respectivamente (Echaide y Valentini, 2000).

La neosporosis bovina en el Perú es altamente prevalente, sobre todo en las principales cuencas lecheras, llegando a $40 \%$ en Cajamarca (Cabrera et al., 2000), 29.6\% en Lima (Silva et al., 2002) y 57\% en Arequipa (Andresen, 1999). Es por ello, que se hace necesario tener un mayor conocimiento de la epidemiología de la neosporosis en nuestro medio, principalmente en cuencas lecheras emergentes, como la provincia de Chachapoyas, Amazonas, la cual cuenta con una población bovina de cerca de 38,000 animales lecheros (INEI, 1996).

El objetivo de este trabajo fue determinar la seroprevalencia de Neospora caninum en vacas lecheras de los distritos de Molinopampa y Leymebamba, provincia de Chachapoyas, y así contribuir a un mejor conocimiento de la epidemiología de la enfermedad en el país.

\section{Materiales y Métodos}

\section{Lugar de estudio}

La fase de campo se realizó en los distritos de Molinopampa y Leymebamba, provincia de Chachapoyas, Amazonas, ubicados sobre los 2,200 msnm. La zona presenta una topografía accidentada, zonas de cordillera y valles interandinos; tiene un clima templado, moderadamente lluvioso y con temperaturas que oscilan entre $10^{\circ}$ a $28^{\circ} \mathrm{C}$. La precipitación pluvial anual varía entre 550 a 1,066 mm, y presenta estaciones climáticas de seca de mayo a agosto y lluviosa de setiembre a abril (INEI, 2002).

\section{Animales}

Se utilizó bovinos lecheros mayores de dos años, mayormente de raza Brown Swiss y criados en sistemas extensivos. Los animales pertenecían a 24 ganaderías, de las cuales 13 correspondieron al distrito de Molinopampa y 11 al distrito de Leymebamba. Todas las fincas ganaderas manifestaron poseer dos perros como mínimo para labores de vigilancia y compañía.

El tamaño muestral fue obtenido según el método de muestreo aleatorio simple, considerando una prevalencia referencial de la neosporosis en Lima de $29.6 \%$ (Silva et al., 2002) y un nivel de confianza de $90 \%$ (Miguel, 1982). El número mínimo de animales a muestrear fue de 227 . 


\section{Recolección de muestras}

La recolección de sangre se llevó a cabo en el mes de abril del 2002, por punción directa de la vena yugular. El suero sanguíneo resultante se almacenó a $-20^{\circ} \mathrm{C}$ y se llevó para su análisis al Laboratorio de Parasitología Veterinaria de la Facultad de Medicina Veterinaria de la Universidad Nacional Mayor de San Marcos.

\section{Detección de anticuerpos contra $N$. caninum}

Los anticuerpos contra $N$. caninum en las muestras de suero diluído en 1:200 fueron detectados mediante la prueba de Inmunofluorescencia Indirecta (IFI) utilizando el antígeno (taquizoítos) proporcionado por la Universidad Complutense de Madrid, España y un conjugado de procedencia comercial (SIGMA).

\section{Análisis de datos}

La seroprevalencia de $N$. caninum se calculó utilizando la fórmula descrita por Thrusfield (1990).

La relación entre la variable edad y la respuesta serológica se analizó mediante la prueba de Regresión Logística usando el programa SPPS 10.0.

\section{Resultados y Discusión}

La prevalencia de anticuerpos contra Neospora caninum en bovinos de dos distritos de la provincia de Chachapoyas fue de $40.4 \%$ (107/265). La presencia de anticuerpos indica que estos animales fueron expuestos al parásito en algún momento de la etapa pre o postnatal. Todas las ganaderías de los distritos de Molinopampa y Leymebamba considerados en el estudio tuvieron animales reactores a $N$. caninum. La distribución de la infección en los animales fue similar en ambos distritos (Cuadro 1).

La alta prevalencia de $N$. caninum encontrada en bovinos de crianza extensiva sugiere la presencia de factores que contribuyen a la transmisibilidad o persistencia del parásito en los bovinos susceptibles. Uno de estos factores podría ser la introducción de animales infectados, ya que a través de informaciones proporcionadas por los ganaderos de la región se supo que en los últimos 10 años han ingresado muchos animales procedentes de la cuenca de Cajamarca y en menor porcentaje de Lima, con el único requisito de estar libres de brucelosis y tuberculosis. Estudios realizados en animales de la cuenca de Cajamarca (Cabrera et al., 2000) y en Lima (Silva et al., 2002) indican que el parásito está ampliamente difundido en esas zonas.

Cuadro 1. Detección de anticuerpos contra Neospora caninum en dos distritos de la provincia de Chachapoyas, Amazonas. 2002

\begin{tabular}{cccccc}
\hline \multirow{2}{*}{ Distrito } & \multirow{2}{*}{$\begin{array}{c}\text { Hatos } \\
(\mathrm{n})\end{array}$} & $\begin{array}{c}\text { Animales } \\
\text { muestreados } \\
\end{array}$ & & \multicolumn{3}{c}{ Animales positivos } \\
\cline { 5 - 6 } & 11 & 150 & 55 & $36.7 \pm 6.5$ & $12.5-66.7$ \\
Leymebamba & 11 & 115 & 52 & $45.2 \pm 7.7$ & $14.3-80.0$ \\
Molinopampa & 13 & 265 & 107 & $40.4 \pm 5.0$ & $12.5-80.0$ \\
\hline Total & 24 & & & & Rango (\%) \\
\hline
\end{tabular}

${ }^{1}$ Intervalo de confianza del $95 \%$ 
Cuadro 2. Seroprevalencia de Neospora caninum en bovinos de dos distritos de la provincia de Chachapoyas, Amazonas según grupo etáreo. 2002

\begin{tabular}{cccc}
\hline Edad (años) & Animales muestreados & Animales positivos & Prevalencia $\pm \operatorname{IC}^{1}(\%)$ \\
\hline$>$ 2 a 3 & 65 & 17 & $26.2 \pm 9.0$ \\
$>$ > 3 a 4 & 80 & 33 & $41.3 \pm 9.1$ \\
$>$ > 4 a 5 & 78 & 35 & $44.9 \pm 9.3$ \\
> 5 & 42 & 22 & $52.4 \pm 12.7$ \\
\hline
\end{tabular}

${ }^{1}$ Intervalo de confianza del 95\%

Los ganaderos también reportan la ocurrencia de metritis, abortos y neumonías, pero lamentablemente no llevan registros por lo que se hace imposible cuantificar las pérdidas o niveles de presentación de problemas infecciosos. Otro factor sería la presencia de perros infectados ya que en las ganaderías visitadas se observaron dos a tres perros como mínimo, fuera de los carnívoros silvestres que pueden ser considerados como posibles fuentes de infección. Wouda et al. (1999) demostró una mayor prevalencia de $N$. caninum en fincas donde habían perros frente a otras sin la presencia de perros.

Existen numerosos estudios de prevalencia de $N$. caninum en ganado lechero, donde las prevalencias varían de 0 a $80 \%$, pero se tiene poca información en ganado de crianza extensiva (Anderson, 2000). Los resultados del presente estudio difieren con los resultados de un estudio reciente realizado en un hato de ganado cebú de crianza extensiva en la zona de Pucallpa donde se reporta una prevalencia de $N$. caninum de $1.5 \%$ (Rivera et al., datos no publicados). Esta diferencia puede deberse a que en los últimos 10 años no han ingresado vacas a ese rebaño, mientras que en los distritos de Molinopampa y Leymebamba ingresaron muchos animales procedentes de áreas ganaderas con alto índice de infección.
La presencia de anticuerpos contra $N$. caninum tuvo una tendencia no significativa a incrementarse con la edad, lo cual es esperado toda vez que a mayor edad existe un mayor tiempo de exposición y la probabilidad de infectarse sería mayor (Cuadro 2). Si bien, el factor edad no mostró diferencias estadísticas al realizar los análisis de regresión logística, se tiene otros estudios que muestran la influencia de la edad con el incremento en la prevalencia de $N$. caninum (Jensen et al., 1999).

También se podría mencionar que la presencia del parásito tiende a ser más frecuente en animales de crianza extensiva por el estrés a que están sometidos, sobre todo en épocas de escasez de pasto (Wouda $e t$ al., 1988).

Estudios realizados sobre la caracterización pecuaria de la zona en estudio revelan su gran potencial para el desarrollo ganadero, sobre todo el aspecto lechero; es así, que se ha incrementado la población de ganado genéticamente mejorado en los últimos años (INEI, 1996), por lo que estos resultados podrían servir de base para determinar el rol del $N$. caninum en estos animales y contribuir a mejorar el estado sanitario del ganado en esta parte del país. 


\section{Conclusiones}

- El parásito Neospora caninum está presente en bovinos de la raza Brown Swiss de los distritos de Molinopampa y Leymebamba, provincia de Chachapoyas, Amazonas, con una prevalencia similar a lo reportado en bovinos de las principales cuencas lecheras del país.

- Todos los hatos evaluados presentaron al menos un animal seropositivo, lo cual estaría indicando que las ganaderías de la zona se encuentran expuestas a una fuente de infección no determinada.

- El distrito de procedencia y la edad del animal no representaron factores de riesgo, pero existe la predisposición de que el animal adquiera la enfermedad conforme avanza la edad.

\section{LITERATURA CITADA}

1. Anderson, M.L; A.G. Andrianarivo; P.A. Conrad. 2000. Neosporosis in cattle. Anim. Reprod. Sci. 60-61: 417-431.

2. Andresen, H. 1999. Neosporosis en el Perú y el Mundo. Rev. Cien. Vet. 15: 11-14.

3. Bjerkas, I.; S.F. Mohn; J. Presthus. 1984. Unidentified cyst-forming sporozoan causing encephalomyelitis and myositis in dogs. Z. Parasitenkd. 70: 271274.

4. Cabrera, M.; P. Ortiz; J. Claxton; D. Williams; A. Trees. 2000. Evidencia serológica de infección por Neospora caninum en ganado vacuno en Perú. IV Congreso Peruano de Parasitología. Lima, Perú. p 212.

5. Echaide, I.; B.S. Valentini. 2000. La neosporosis bovina en los rodeos lecheros de la cuenca central Argentina. Chacra 832: 130.
6. Instituto Nacional de Estadística e Informática (INEI). 1996. Censo Nacional Agropecuario INEI, Ministerio de Agricultura. Lima. Tomo III y IV: 21462235.

7. Instituto Nacional de Estadística e Informática (INEI). 2002. Directorio Nacional de Municipalidades Provinciales, Distritales y de Centro de Poblado Menor. INEI. Lima. p 17.

8. Jensen, A.M.; C. Bjorkman; A.M. Kjeldsen; A. Wedderkopp; C. Willadsen; A. Uggla; P. Lind. 1999. Associations of Neospora caninum seropositivity with gestation number and pregnancy outcome in Danish dairy herds. Prev. Vet. Med. 40: 151- 163.

9. McAllister, M.; J.P. Dubey; D.S. Lindsay; W. Jolley; R. Wills; A.M. McGuire. 1998. Dogs are definitive host of Neospora caninum. Int. J. Parasitol. 28: 1473-1478.

10. Miguel, O. 1982. Técnicas de amostragem para exames laboratoriais. Hyg. Alim. 1: 413-415.

11. Silva, P.; A. Chávez; H. Rivera; E. Casas. 2002. Seroprevalencia de Neospora caninum en bovinos lecheros del Valle de Lima. RIVEP 13: 51-55.

12. Thilsted, J.P.; J.P. Dubey. 1989. Neosporosis-like abortions in a herd of dairy cattle. J. Vet. Diagn. Invest. 1: 205-209.

13. Thrusfield, M. 1990. Epidemiología Veterinaria. Ed. Acribia. p 228-230.

14. Wouda, W; A. Moen; H. Schukken. 1998. Abortion risk in progeny of cows after a Neospora caninum epidemic. Theriogenology 49: 1311-1316.

15. Wouda, W.; T.H. Dijkstra; A.M.H. Kramer; C. Van Maanen; J.M.A. Brinkhof. 1999. Seroepidemiological evidence for a relationship between Neospora caninum infections in dogs and cattle. Internat. J. Parasitology 29: 16771682. 